Check for updates

Cite this: RSC Adv., 2017, 7, 30573

Received 5th April 2017

Accepted 2nd June 2017

DOI: $10.1039 / c 7 r a 03884 d$

rsc.li/rsc-advances

\section{Influence of pendant 2-[1,2,4]triazol-4-yl- ethylamine and symmetrical bis(pyrazol) ligands on dimensional extension of POM-based compounds $\uparrow$}

\begin{abstract}
Aixiang Tian, (DD* Huaiping Ni, Xuebin Ji, Yan Tian, Guocheng Liu and Jun Ying*
Through utilizing pendant 2-[1,2,4]triazol-4-yl-ethylamine (tea) and two kinds of bis(pyrazol) ligand, five new polyoxometalate (POM)-based compounds $\left[\mathrm{Cu}_{3} \mathrm{~K}_{2}(\mathrm{tea})_{2}(\mathrm{OH})_{4}\left(\mathrm{H}_{2} \mathrm{Mo}_{8} \mathrm{O}_{27}\right)\right] \quad(1), \quad[\mathrm{Ag}(\mathrm{tea})(\beta$ $\left.\mathrm{H}_{2} \mathrm{Mo}_{8} \mathrm{O}_{26}\right)_{0.5}$ (2), [Ag(tea) $\left.\left(\mathrm{H}_{2} \mathrm{O}\right)\left(\gamma-\mathrm{H}_{2} \mathrm{Mo}_{8} \mathrm{O}_{26}\right)_{0.5}\right]$ (3), [Cu( $\left.\left.\mathrm{H}_{2} \mathrm{bdpm}\right)\left(\beta-\mathrm{Mo}_{8} \mathrm{O}_{26}\right)_{0.5}\right]$ (4) and $\left[\mathrm{Ag}_{2}(\mathrm{Hbhpe})(\theta-\right.$ $\left.\mathrm{Mo}_{8} \mathrm{O}_{26}\right)_{0.5} \mathrm{~J} \quad$ (5) $\left(\mathrm{H}_{2} \mathrm{bdpm}=1,1^{\prime}\right.$-bis(3,5-dimethyl-1H-pyrazol-4-yl)methane, $\mathrm{H}_{2}$ bhpe = 1,2-bis $(1 \mathrm{H}$ pyrazolate)ethane) were synthesized under hydrothermal conditions and characterized by single-crystal X-ray diffraction. In compound 1, three $\mathrm{Cu}^{\prime \prime}$ are fused by two tea and two $\mathrm{OH}^{-}$moieties to form a tri-nuclear cluster $\left[\mathrm{Cu}_{3}(\mathrm{tea})_{2}(\mathrm{OH})_{2}\right]^{4+}$. The $\mathrm{Mo}_{8}$ anions link each other through sharing terminal $\mathrm{O}$ atoms to build an Mo-chain. The tri-nuclear clusters are further connected by an Mo-chain and $\mathrm{K}^{+}$ions to form a 3D framework. In compound 2, two $\mathrm{Ag}^{+}$ions are fused by two tea ligands to construct a bi-nuclear subunit, which are linked by $\beta-\mathrm{Mo}_{8}$ anions alternately to form a $1 \mathrm{D}$ chain. In compound 3 , there exists a bi-nuclear $\mathrm{Ag}^{+}$cluster $\left[\mathrm{Ag}_{2}(\mathrm{tea})_{2}\right]^{2+}$. The $\gamma-\mathrm{Mo}_{8}$ anions link bi-nuclear $\mathrm{Ag}^{+}$clusters alternately and a $1 \mathrm{D}$ chain is constructed. Furthermore, each $\left[\mathrm{Ag}_{2}(\mathrm{tea})_{2}\right]^{2+}$ offers two additional $\mathrm{N}$ donors to connect two anions through $\mathrm{Mo}-\mathrm{N}$ bonds. In compound 4, two $1 \mathrm{D}$ zigzag $\mathrm{Cu}-\mathrm{H}_{2}$ bdpm chains cover one 1D inorganic Mo-chain up and down to build a "hamburger-like" chain. The adjacent hamburger chains share the same $\mathrm{Cu}$ atoms to build a 2D structure. In compound 5, there exists a bi-nuclear $\left[\mathrm{Ag}_{2}(\mathrm{Hbhpe})_{2}\right]^{2+}$ cycle and a tetra-nuclear $\left[\mathrm{Ag}_{4}(\mathrm{Hbhpe})_{4}\right]^{4+}$ cycle. The bi-nuclear cycles and tetra-nuclear cycles alternately connect to form 1D metal-organic chains, which are further linked by $\theta-\mathrm{MO}_{8}$ anions to construct a 2D layer. The electrochemical and photocatalytic properties of compounds 1-5 are studied.
\end{abstract}

\section{Introduction}

Polyoxometalates (POMs) have attracted extensive attention as an emerging branch of inorganic chemistry because of their diverse structures ${ }^{\mathbf{1}}$ and extensive applications in catalysis, medicine, magnetism, photochemistry and other fields. ${ }^{2}$ POMs can provide abundant $\mathrm{O}$ donors to connect transition metal complexes (TMCs) to construct metal-organic complex materials with various structures and properties. ${ }^{3}$ Among the abundant types of POM, some classical anions have received greater attention, such as the Keggin, Wells-Dawson, isopolymolybdate and Anderson anions. In addition, the octamolybdate-TMCs are an important branch. The octamolybdate anions have eight isomers: $\alpha, \beta, \gamma, \delta, \varepsilon, \zeta, \eta$ and $\theta,{ }^{4}$ which can induce novel structures. Interestingly, two or more isomers can be captured in one octamolybdate-TMC compound. ${ }^{5}$ Furthermore, the

Department of Chemistry, Bohai University, Jinzhou, 121000, P. R. China. E-mail: tian@bhu.edu.cn; ying@bhu.edu.cn

$\dagger$ Electronic supplementary information (ESI) available: IR spectra, CV data and additional figures. CCDC 1531320 for 1, 1531323 for 2, 1531324 for 3, 1531321 for 4, 1531322 for $\mathbf{5}$. For ESI and crystallographic data in CIF or other electronic format see DOI: $10.1039 / \mathrm{c} 7 \mathrm{ra} 03884 \mathrm{~d}$ octamolybdate anions may share the same $\mathrm{O}$ atoms to build new Mo-chains. ${ }^{6}$ Thus, the design and syntheses of octamolybdate-TMCs allow fascinating structures to be constructed to enrich the POM field. For example, Zubieta and coworkers have published numerous relevant papers concerning the use of octamolybdate ions as building blocks for the design of an extended network. ${ }^{7}$

In the synthetic strategy used for forming octamolybdateTMCs, the choice of appropriate organic ligands is essential and important. Flexible organic molecules have become more popular in building high-dimensional frameworks, especially containing two symmetrical coordination groups. ${ }^{8}$ Organic ligands of this series contain flexibility and more coordination sites, conducive to constructing novel topologies. Up until now, a large number of flexible organic molecules containing two symmetrical coordination groups have been used, such as flexible bis(triazole), ${ }^{9}$ bis(imidazole) ${ }^{10}$ and bis(tetrazole) ligands. ${ }^{11}$ In our previous work, we have utilized a series of symmetric flexible bis(triazole) ligands to build POM-based compounds. ${ }^{12}$ On the other hand, pendant organic ligands containing only one coordination group are scarcely used in octamolybdate-based compounds. Compared with flexible ligands with two symmetrical coordination groups, the pendant 
ligands may induce structures with low dimensionalities. ${ }^{13}$ Thus, it is interesting and appealing to explore the influence of pendant ligand with one coordination group and flexible ligands with two symmetrical coordination groups on structural dimensionalities. In this work, we chose two kinds of ligand as the organic moiety with which to modify octamolybdate anions: pendant 2-[1,2,4]triazol-4-yl-ethylamine (tea) and the bis(pyrazol) ligands, 1,2-di(1H-pyrazol-4-yl)ethane (Hbhpe) and bis(3,5dimethyl-1 $H$-pyrazol-4-yl)methane $\left(\mathrm{H}_{2} \mathrm{bdpm}\right)$.

Herein, by introducing pendant tea and flexible Hbhpe and $\mathrm{H}_{2}$ bdpm to the octamolybdate system, five new POM-based TMCs have been obtained: $\left[\mathrm{Cu}_{3} \mathrm{~K}_{2}(\text { tea })_{2}(\mathrm{OH})_{4}\left(\mathrm{H}_{2} \mathrm{Mo}_{8} \mathrm{O}_{27}\right)\right]$ (1), $\left[\mathrm{Ag}\right.$ (tea) $\left.\left(\beta-\mathrm{H}_{2} \mathrm{Mo}_{8} \mathrm{O}_{26}\right)_{0.5}\right]$ (2), [Ag(tea) $\left.\left(\mathrm{H}_{2} \mathrm{O}\right)\left(\gamma-\mathrm{H}_{2} \mathrm{Mo}_{8} \mathrm{O}_{26}\right)_{0.5}\right]$ (3), $\left[\mathrm{Cu}\left(\mathrm{H}_{2} \mathrm{bdpm}\right)\left(\beta-\mathrm{Mo}_{8} \mathrm{O}_{26}\right)_{0.5}\right]$ (4) and $\left[\mathrm{Ag}_{2}(\mathrm{Hbhpe})\left(\theta-\mathrm{Mo}_{8} \mathrm{O}_{26}\right)_{0.5}\right]$ (5). The electrochemical and photocatalytic properties of these five compounds were also studied.

\section{Experimental}

\section{Materials and methods}

All reagents and solvents for syntheses were purchased from commercial sources and used as received without further purification. Elemental analyses were achieved using a PerkinElmer 240C elemental analyzer, and Fourier-transform infrared (FT-IR) spectra were recorded on a Varian FT-IR 640 spectrometer ( $\mathrm{KBr}$ pellets). Ultraviolet/visible (UV/Vis) absorption spectra were obtained using a SP-1601 UV/Vis spectrophotometer. Electrochemical measurements and data collection were performed using a CHI 440 electrochemical workstation connected to a Digital-586 personal computer. A conventional three-electrode system was used with a saturated calomel electrode (SCE) as the reference electrode and a Pt wire as the counter electrode. Modified carbon paste electrodes
(CPEs) of the title compounds were used as the working electrodes.

\section{X-ray crystallography}

Crystallographic data for compounds 1-5 were collected on a Bruker SMART APEX II with Mo K $\alpha(\lambda=0.71073 \AA)$ by $\omega$ and $\theta$ scan mode at $293 \mathrm{~K}$. All structures were solved by direct methods and refined on $F^{2}$ by full-matrix least squares using the SHELXL package. ${ }^{\mathbf{1 4}}$ For compounds $\mathbf{1 - 5}$, the hydrogen atoms attached to water molecules were not located, but were included in the structure factor calculations, as well as disordered Ag1 and $\mathrm{Ag} 2$ atoms in compound 5. Detailed crystal data and structures refinement for 1-5 are given in Table 1. Selected bond lengths and angles are listed in Table S1. Crystallographic data for the structures reported in this paper have been deposited in the Cambridge Crystallographic Data Centre (CCDC), with CCDC numbers of 1531320 for 1, 1531323 for 2, 1531324 for 3, 1531321 for $\mathbf{4}$ and 1531322 for $\mathbf{5}$. $\dagger$

\section{Preparation of compounds 1-5}

Synthesis of $\left[\mathrm{Cu}_{3} \mathrm{~K}_{2}(\text { tea })_{2}(\mathrm{OH})_{\mathbf{4}}\left(\mathrm{H}_{2} \mathrm{Mo}_{\mathbf{8}} \mathrm{O}_{27}\right)\right]$ (1). A mixture of $\mathrm{CuCl}_{2} \mathrm{H}_{2} \mathrm{O}(0.076 \mathrm{~g}, 0.446 \mathrm{mmol})$, KCl $(0.02 \mathrm{~g}, 0.27 \mathrm{mmol})$, $\mathrm{Na}_{3}\left(\mathrm{CrMo}_{6} \mathrm{O}_{24} \mathrm{H}_{6}\right) \cdot 8 \mathrm{H}_{2} \mathrm{O}(0.1 \mathrm{~g}, 0.081 \mathrm{mmol})$, tea (0.02 g, 0.098 $\mathrm{mmol})$ and $\mathrm{H}_{2} \mathrm{O}(10 \mathrm{~mL})$ was stirred for $40 \mathrm{~min}$ in air at room temperature. The $\mathrm{pH}$ value of the solution was adjusted to about 2.5 with $1.0 \mathrm{~mol} \mathrm{~L}^{-1} \mathrm{HCl}$ and sodium hydroxide. The suspension was sealed in a Teflon-lined autoclave $(25 \mathrm{~mL})$ and kept at $160{ }^{\circ} \mathrm{C}$ for 5 days. Green clavate crystals of 1 (yield $48 \%$ based on Mo) were obtained. Elemental analysis (\%) calc. for $1 \mathrm{C}_{8} \mathrm{H}_{26}$ $\mathrm{N}_{8} \mathrm{Cu}_{3} \mathrm{~K}_{2} \mathrm{Mo}_{8} \mathrm{O}_{31}$ (1766.68): C 5.44, $\mathrm{H}$ 1.48, N 6.34. Found: C 5.49, $\mathrm{H}$ 1.43, N, 6.39. IR ( $\mathrm{KBr}$ pellet, $\mathrm{cm}^{-1}$ ): $3086(\mathrm{w}), 2358(\mathrm{w})$,

Table 1 Crystal data and structure refinement for compounds 1-5

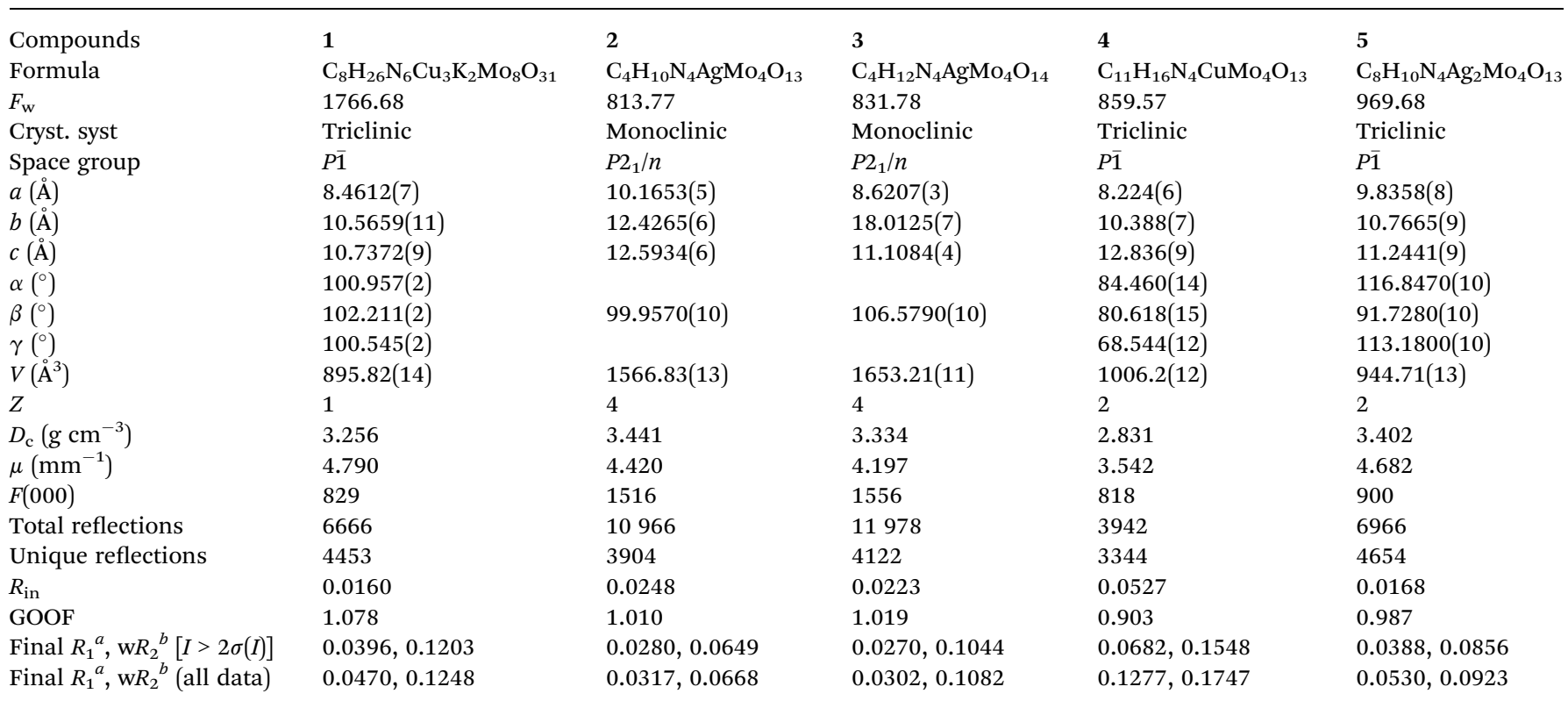

${ }^{a} R_{1}=\sum|| F_{\mathrm{o}}|-| F_{\mathrm{c}}|| / \sum\left|F_{\mathrm{o}}\right| \cdot{ }^{b} \mathrm{w} R_{2}=\left\{\sum\left[\mathrm{w}\left(F_{\mathrm{o}}{ }^{2}-{F_{\mathrm{c}}}^{2}\right)^{2}\right] / \sum\left[\mathrm{w}\left(F_{\mathrm{o}}{ }^{2}\right)^{2}\right]\right\}^{1 / 2}$. 
1626 (m), 1506 (m), 1436 (s), 1116 (w), 1018 (m), 931 (s), 879 (s), 745 (s), 627 (s).

Synthesis of $\left[\mathrm{Ag}(\mathrm{tea})\left(\boldsymbol{\beta}-\mathrm{H}_{2} \mathrm{Mo}_{\mathbf{8}} \mathrm{O}_{26}\right)_{\mathbf{0 . 5}}\right]$ (2). A mixture of $\mathrm{AgNO}_{3}$ $(0.076 \mathrm{~g}, 0.086 \mathrm{mmol}),\left[\left(n-\mathrm{C}_{4} \mathrm{H}_{9}\right)_{4} \mathrm{~N}\right]_{2}\left[\mathrm{Mo}_{6} \mathrm{O}_{19}\right]$ (0.1 g, 0.154 $\mathrm{mmol})$, tea $(0.1 \mathrm{~g}, 0.625 \mathrm{mmol})$ and $\mathrm{H}_{2} \mathrm{O}(10 \mathrm{~mL})$ was stirred for $40 \mathrm{~min}$ in air at room temperature. The $\mathrm{pH}$ value of the solution was then adjusted to 3.2 with $1 \mathrm{M} \mathrm{HNO}_{3}$ and ammonium hydroxide. White block crystals of 2 were obtained. Elemental analysis (\%) calc. for $\mathrm{C}_{4} \mathrm{H}_{10} \mathrm{~N}_{4} \mathrm{AgMo}_{4} \mathrm{O}_{13}$ (813.77): C 5.90, $\mathrm{H} 1.24$, N 6.88. Found: C 5.83, H 1.28, N 6.82. IR (KBr pellet, $\left.\mathrm{cm}^{-1}\right): 3111$ (m), 2364 (m), 1637 (m), 1440 (m), $1328(\mathrm{w}), 1284(\mathrm{w}), 1205(\mathrm{w})$, $1120(\mathrm{w}), 968(\mathrm{~s}), 879(\mathrm{~s}), 754(\mathrm{~s})$ and $565(\mathrm{~s})$.

Synthesis of $\left[\mathrm{Ag}(\mathrm{tea})\left(\mathrm{H}_{2} \mathrm{O}\right)\left(\gamma-\mathrm{H}_{2} \mathrm{Mo}_{8} \mathrm{O}_{26}\right)_{0.5}\right]$ (3). A mixture of $\mathrm{AgNO}_{3}(0.076 \mathrm{~g}, 0.086 \mathrm{mmol}),\left[\left(n-\mathrm{C}_{4} \mathrm{H}_{9}\right)_{4} \mathrm{~N}\right]_{2}\left[\mathrm{Mo}_{6} \mathrm{O}_{19}\right](0.1 \mathrm{~g}$, $0.154 \mathrm{mmol})$, tea $(0.02 \mathrm{~g}, 0.098 \mathrm{mmol})$ and $\mathrm{H}_{2} \mathrm{O}(10 \mathrm{~mL})$ was stirred for $40 \mathrm{~min}$ in air at room temperature. The $\mathrm{pH}$ value of the solution was adjusted to about 2.6 with $1.0 \mathrm{~mol} \mathrm{~L}^{-1} \mathrm{HNO}_{3}$ and ammonium hydroxide. The suspension was sealed in a Teflon-lined autoclave $(25 \mathrm{~mL})$ and kept at $160{ }^{\circ} \mathrm{C}$ for 5 days. Yellow-black crystals of 3 (yield $35 \%$ based on Mo) were obtained. Elemental analysis (\%) calc. for $3 \mathrm{C}_{4} \mathrm{H}_{12} \mathrm{~N}_{4} \mathrm{OAgMo}_{4} \mathrm{O}_{13}$ (831.78): C 5.78, H 1.45, N 6.74. Found: C 5.71, H 1.48, N, 6.69. IR (KBr pellet, $\mathrm{cm}^{-1}$ ): 3390 (w), 2451 (w), 1626 (s), 1558 (s), 1500 (s), 1448 (s), 1340 (s), 1217 (s), 1112 (s), 1024 (s), 938 (s), 825 (s), 673 (s) and $554(\mathrm{~s})$.

Synthesis of $\left[\mathrm{Cu}\left(\mathrm{H}_{2} \mathbf{b d p m}\right)\left(\boldsymbol{\beta}-\mathrm{Mo}_{8} \mathrm{O}_{26}\right)_{\mathbf{0 . 5}}\right]$ (4). The compound 4 was prepared in the same way as compound $\mathbf{1}$ except that $\mathrm{H}_{2}$ bdpm ( $0.1 \mathrm{~g}, 0.625 \mathrm{mmol}$ ) was used instead of tea. The $\mathrm{pH}$ value of the solution was then adjusted to 2.2 with $1.0 \mathrm{~mol} \mathrm{~L}^{-1}$ $\mathrm{NaOH}$ and HCl. Green clavate crystals of 4 (yield 30\% based on Mo) were obtained. Elemental analysis (\%) calc. for $4 \mathrm{C}_{11} \mathrm{H}_{16}$ $\mathrm{N}_{4} \mathrm{CuMo}_{4} \mathrm{O}_{13}$ (859.57): C 15.37, H 1.88, N 6.52. Found: C 15.31, H 1.92, N, 6.46. IR (KBr pellet, $\mathrm{cm}^{-1}$ ): 3340 (m), $2920(\mathrm{w}), 1634$ (m), $1446(\mathrm{~s}), 1271(\mathrm{w}), 1188(\mathrm{~m}), 1039(\mathrm{w}), 970(\mathrm{~s}), 880(\mathrm{~s}), 761(\mathrm{~s})$ and 542 (s).

Synthesis of $\left[\mathrm{Ag}_{2}(\mathrm{Hbhpe})\left(\boldsymbol{\theta}-\mathbf{M o}_{\mathbf{8}} \mathrm{O}_{26}\right)_{0.5}\right](5)$. Compound 5 was prepared in a similar way to 2, except that Hbhpe $(0.02 \mathrm{~g}, 0.098$ $\mathrm{mmol}$ ) was used instead of tea. The $\mathrm{pH}$ value of the solution was adjusted to about 1.6 with $1.0 \mathrm{~mol} \mathrm{~L}^{-1} \mathrm{HNO}_{3}$ and ammonium hydroxide. The suspension was sealed in a Teflon-lined autoclave $(25 \mathrm{~mL})$ and kept at $170{ }^{\circ} \mathrm{C}$ for 4 days. Pink rhombus crystals of 5 (yield $20 \%$ based on Mo) were obtained. Elemental analysis (\%) calc. for $5 \mathrm{C}_{8} \mathrm{H}_{10} \mathrm{~N}_{4} \mathrm{Ag}_{2} \mathrm{Mo}_{4} \mathrm{O}_{13}$ (969.68): $\mathrm{C} 9.91, \mathrm{H}$ 1.04, N 5.78. Found: C 9.85, H 1.08, N, 5.72. IR (KBr pellet, $\mathrm{cm}^{-1}$ ): $3327(\mathrm{w}), 2931(\mathrm{w}), 2355(\mathrm{w}), 1647(\mathrm{~m}), 1560(\mathrm{~m}), 1442$ (m), $1286(\mathrm{w}), 1186(\mathrm{w}), 1031$ (w), 964 (s), 871 (s), 766 (s) and $534(\mathrm{~s})$.

Preparation of 1- to 5-CPEs. Compound 1 modified carbon paste electrode (1-CPE) was synthesized as follows: graphite powder (100 mg) and compound 1 (90 $\mathrm{mg}$ ) were mixed and ground together using an agate mortar and pestle for approximately $1 \mathrm{~h}$ to achieve the entire mixture. Then, $0.10 \mathrm{~mL}$ of the paraffin oil was added and stirred with a glass rod. The homogenized mixture was encapsulated to a $3 \mathrm{~mm}$ inner diameter hollow glass pipe with a length of $0.8 \mathrm{~cm}$. The pipe surface was smoothed with weighing paper, and the electrical contact was assembled with the copper rod. In a similar process, 2-, 3- and 4-CPEs were synthesized with compounds 2, 3,4 and 5.

\section{Results and discussion}

\section{Structural description}

Crystal structure of compound 1. X-ray crystal structure analysis reveals that the asymmetric unit of compound 1 consists of one $\left[\mathrm{Mo}_{8} \mathrm{O}_{26}\right]^{4-}$ anion (abbreviated as $\mathrm{Mo}_{8}$ ), three $\mathrm{Cu}^{2+}$ ions, two tea ligands, two $\mathrm{K}^{+}$cations and four hydroxy groups (Fig. 1). The valence sum calculations ${ }^{15}$ show that all Mo atoms are in the $+\mathrm{VI}$ oxidation state, while all $\mathrm{Cu}$ atoms are in the + II oxidation state.

In compound 1, there are two crystallographically independent $\mathrm{Cu}^{2+}$ ions (Cu1 and $\mathrm{Cu} 2$ ), with two kinds of coordination geometries. Cu1 ion is six-coordinated by one $\mathrm{N} 2$ atom from one tea ligand, three $\mathrm{O}$ atoms (O8, O12 and $\mathrm{O} 13)$ from two $\mathrm{Mo}_{8}$ anions and two hydroxy groups, adopting a distorted octahedral geometry. The Cu2 ion is also six-coordinated by two N1 atoms from two tea ligands, two $\mathrm{O} 10$ atoms from two $\mathrm{Mo}_{8}$ anions and two hydroxy groups. The $\mathrm{Cu}-\mathrm{N}$ distances are 1.943(5) and 2.052(6) $\AA$, while the $\mathrm{Cu}-\mathrm{O}$ bond distances are in the range of 1.924(5)-2.394(5) $\AA$. The $\mathrm{N}-\mathrm{Cu}-\mathrm{N}$ angle is 179.999(1) and the O$\mathrm{Cu}-\mathrm{O}$ angles are in the range $87.46(19)-180.00(1)^{\circ}$ (Table S1 $\dagger$ ).

In compound 1 , the tea ligand uses its two adjacent nitrogen donors to coordinate two $\mathrm{Cu}^{2+}$ ions. Two tea molecules are fused by three $\mathrm{Cu}$ atoms to form a linear tri-nuclear $\left[\mathrm{Cu}_{3}\right.$ $\left.(\text { tea })_{2}(\mathrm{OH})_{2}\right]^{4+}$ subunit, in which two tea are located top and bottom (Fig. 1). This tri-nuclear cluster is a discrete unit. No

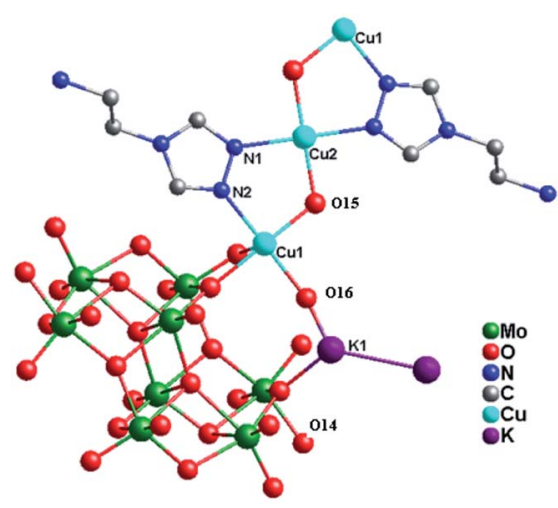

Fig. 1 Ball/stick view of the asymmetric unit of compound 1. The hydrogen atoms are omitted for clarity.

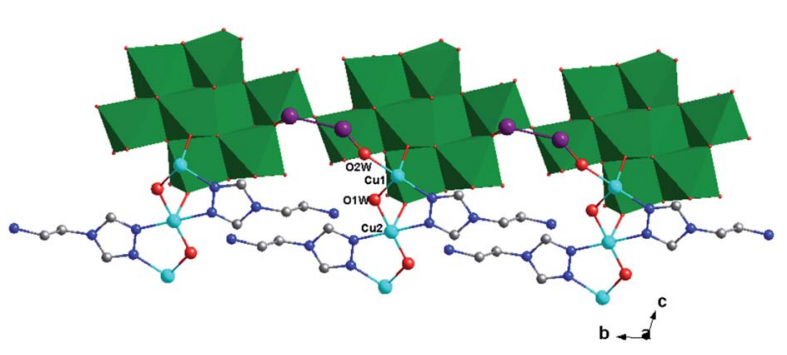

Fig. 2 1D structure of 1 containing Mo-chain (green polyhedron). 


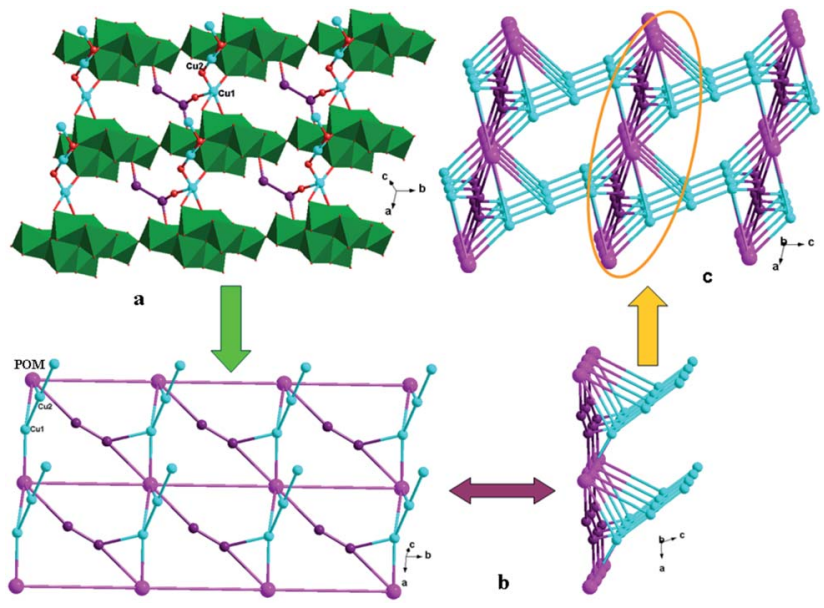

Fig. 3 (a) 2D grid-like layer of 1. (b) Schematic view of the 2D layer viewing along the different given directions. (c) 3D framework of 1.

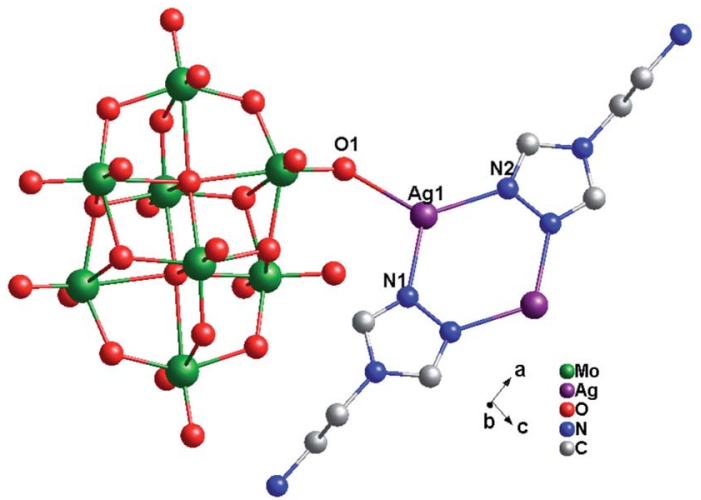

Fig. 4 Ball/stick view of the asymmetric unit of compound 2. The hydrogen atoms are omitted for clarity.

dimensional extension of the metal-organic subunit is possible because the $-\mathrm{NH}_{2}$ group is difficult to link metal ions. Furthermore, the adjacent $\mathrm{Mo}_{8}$ anions share the same 014 atoms to form an infinite Mo-chain (Fig. 2). The tri-nuclear $\left[\mathrm{Cu}_{3}(\mathrm{tea})_{2}(\mathrm{OH})_{2}\right]^{4+}$ clusters are linked by an Mo-chain and $\mathrm{K}^{+}$ atoms to form a 2D layer of $\mathbf{1}$ (Fig. 3a and b). Adjacent layers share the same $\mathrm{Cu}^{2+}$ ions to construct a 3D framework, as shown in Fig. 3c. In compound 1, the tri-nuclear metal-organic subunit is only a $0 \mathrm{D}$ cluster, with contributions from the Mochain and $\mathrm{K}^{+}$ions to build a $3 \mathrm{D}$ structure.

Crystal structure of compound 2. Single-crystal X-ray structure analysis reveals that compound 2 consists of half a $\beta-\mathrm{Mo}_{8}$ anion, one $\mathrm{Ag}^{+}$ion and one tea ligand (Fig. 4). The $\beta-\mathrm{Mo}_{8}$ anion contains six $\left\{\mathrm{MoO}_{6}\right\}$ octahedra. All Mo atoms are in the $+\mathrm{VI}$ oxidation state and the $\mathrm{Ag}$ atoms are in the $+\mathrm{I}$ oxidation state according to valence sum calculations. ${ }^{15}$ In order to balance the charge, two protons have been added in the formula of 2 .

In compound 2 , there exist only one crystallographically independent $\mathrm{Ag}^{+}$ion. The Ag1 ion adopts a "Y"-type geometry, coordinated with two N atoms (N1 and N2) from one tea ligand and one $\mathrm{O} 1$ atom from one $\mathrm{Mo}_{8}$ anion. The $\mathrm{Ag}-\mathrm{N}$ bond

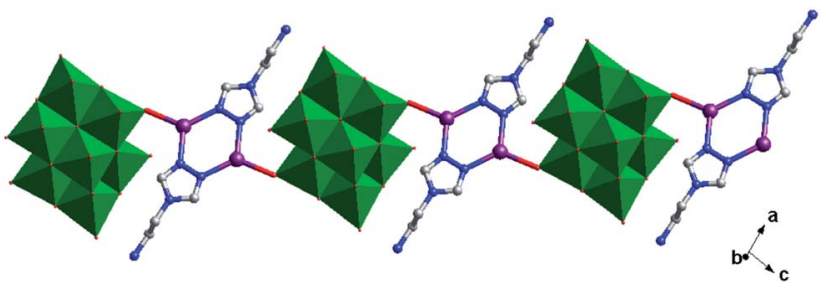

Fig. 5 1D chain of 2 .

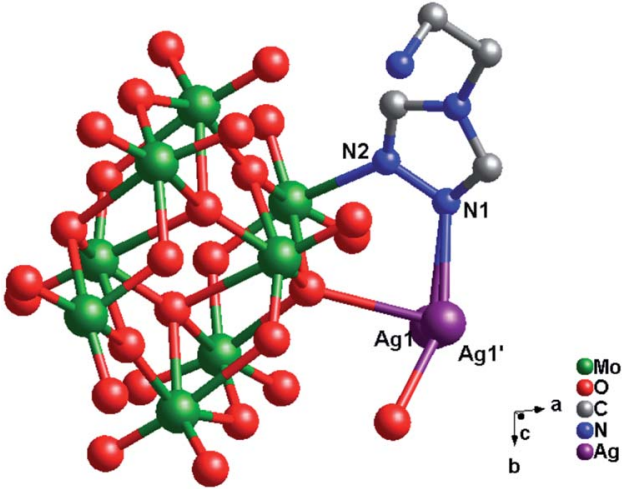

Fig. 6 Ball/stick view of the asymmetric unit of compound 3. The hydrogen atoms are omitted for clarity.

distances range from 2.221(4) to 2.253(4) $\AA$, while the $\mathrm{Ag}-\mathrm{O}$ bond distance is 2.320(3) $\mathrm{A}$ and the $\mathrm{N}-\mathrm{Ag}-\mathrm{N}$ angle is $121.40(13)^{\circ}$ (Table $\mathrm{S} 1 \dagger$ ).

In compound 2 , one tea ligand still provides two successive $\mathrm{N}$ atoms to link two $\mathrm{Ag}^{+}$ions. Two tea molecule fuse two $\mathrm{Ag}^{+}$ions and a $0 \mathrm{D}$ bi-nuclear cluster is constructed. The $-\mathrm{NH}_{2}$ still does not to coordinate with $\mathrm{Ag}^{+}$ions and the metal-organic dimension is not extended. However, $\beta-\mathrm{Mo}_{8}$ plays the linking role in connecting adjacent bi-nuclear $\mathrm{Ag}^{+}$clusters through Ag1-O1 bonds to build a 1D chain of 2, as shown in Fig. 5. Furthermore, the adjacent $1 \mathrm{D}$ chains are linked by hydrogen-bonding interactions (O5 $\cdots \mathrm{Ag} 1=2.923 \AA$ ) to construct a 2D supramolecular layer (Fig. S1†).

Crystal structure of compound 3. Single-crystal X-ray structure analysis reveals that compound 3 consists of half a $\gamma-\mathrm{Mo}_{8}$ anion, one $\mathrm{Ag}^{+}$ion, one tea ligand and one coordinated water molecule (Fig. 6). The $\gamma-\mathrm{Mo}_{8}$ anion contains six $\left\{\mathrm{MoO}_{6}\right\}$ octahedral and two $\left\{\mathrm{MoO}_{5}\right\}$ subunits at both ends. All Mo atoms are also in the + VI oxidation state and the $\mathrm{Ag}$ atoms are in the $+\mathrm{I}$ oxidation state according to valence sum calculations. ${ }^{15}$ In order to balance the charge, two protons have been added in the formula of 3 .

In compound 3 , one $\mathrm{Ag}$ atom disorders into two (Ag1 and Ag1'), with each site half occupied. The Ag1 ion is fourcoordinated by one $\mathrm{N} 1$ atom from one tea, two $\mathrm{O}$ atoms (O6 and O9) from two $\gamma-\mathrm{Mo}_{8}$ anions and one $\mathrm{O}$ atom from one coordinated water (O1W), adopting a distorted quadrangle geometry. Around the $\mathrm{Ag}^{+}$atom, the $\mathrm{Ag}-\mathrm{O}$ bond distances are in the range 2.266(4)-2.493(4) $\AA$, while the $\mathrm{Ag}-\mathrm{N}$ bond distances are in the range $2.347(5)-2.491(4) \AA$. The $\mathrm{N}(1)-\mathrm{Ag}(1)-\mathrm{N}$ angle is 


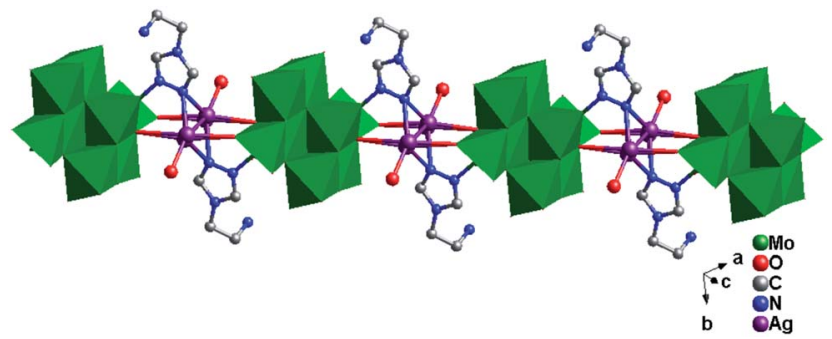

Fig. 7 1D organic-metal chain of 3 .

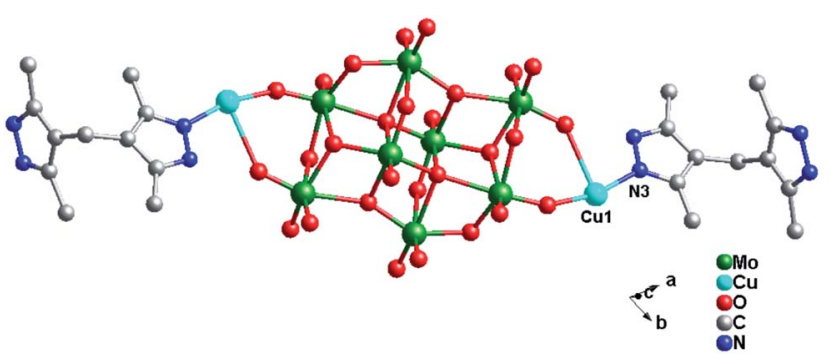

Fig. 8 Ball/stick view of the asymmetric unit of compound 4 . The hydrogen atoms are omitted for clarity.

$114.14(12)^{\circ}$, while the $\mathrm{N}-\mathrm{N}-\mathrm{Ag}$ angles range from $110.2(3)$ to 123.8(3) (Table S1 †).

The tea in 3 also offers two $\mathrm{N}$ atoms ( $\mathrm{N} 1$ and $\mathrm{N} 2$ ) to link two metal ions. However, unlike compound 2, only $\mathrm{N} 1$ links one $\mathrm{Ag}^{+}$ ion, while N2 links one Mo2 atom. Two tea offer two N1 atoms two fuse two $\mathrm{Ag}$ atoms, and a bi-nuclear $\mathrm{Ag}^{+}$cluster $\left[\mathrm{Ag}_{2}(\mathrm{tea})_{2}\right]^{2+}$ is formed. The bi-nuclear $\mathrm{Ag}^{+}$cluster through $\mathrm{Ag}-\mathrm{O} 9$ and $\mathrm{Ag}-\mathrm{O} 6$ bonds connect two adjacent $\gamma-\mathrm{Mo}_{8}$ to construct a 1D chain (Fig. 7). Furthermore, the left N2 donors in $\left[\mathrm{Ag}_{2}(\mathrm{tea})_{2}\right]^{2+}$ coordinate with two $\gamma-\mathrm{Mo}_{8}$ anions through two Mo2-N2 bonds. This linking style of Mo-N bonds is a structural feature of $\gamma-\mathrm{Mo}_{8}$ anion, which owns two $\left\{\mathrm{MoO}_{5}\right\}$ subunits at both ends. The existence of Mo-N bonds strengthens the stability of 3 . The adjacent $1 \mathrm{D}$ chains are still further linked by hydrogen-bonding interactions $(\mathrm{O} 1 \mathrm{~W} \cdots \mathrm{O} 7=$ $2.868 \AA$ A) to construct a 2D supramolecular layer (Fig. S2†).

Crystal structure of compound 4. Single-crystal X-ray structure analysis reveals that compound 4 consists of half a $\beta-\mathrm{Mo}_{8}$ anion, one $\mathrm{Cu}^{2+}$ ion and one $\mathrm{H}_{2}$ bdpm ligand (Fig. 8). Valence sum calculations ${ }^{15}$ show that all Mo atoms are in the $+\mathrm{VI}$ oxidation state and all $\mathrm{Cu}$ atoms are in the $+\mathrm{II}$ oxidation state. Compound 4 involves only one crystallographically independent $\mathrm{Cu}$ ion. $\mathrm{Cu} 1$ is six-coordinated with two $\mathrm{N}$ donors ( $\mathrm{N} 1$ and N3) from two $\mathrm{H}_{2}$ bdpm ligands and four terminal $\mathrm{O}$ atoms (O3, $\mathrm{O} 7, \mathrm{O} 9$ and $\mathrm{O} 11$ ) from three $\mathrm{\beta}-\mathrm{Mo}_{8}$ anions. The $\mathrm{Cu}-\mathrm{O}$ distances are in the range 1.948(10)-1.953(10) $\AA$, while the $\mathrm{Cu}-\mathrm{N}$ distances range from 1.955(14) to 1.956(14) $\AA$. The $\mathrm{O}-\mathrm{Cu}-\mathrm{O}$ angle is 86.8(4) ${ }^{\circ}$, while the $\mathrm{N}-\mathrm{Cu}-\mathrm{N}$ angle is $93.1(6)^{\circ}$ (Table $\mathrm{S} 1 \dagger$ ).

In compound $\mathbf{4}$, the adjacent $\beta-\mathrm{Mo}_{8}$ anions connect each other through sharing two bridging $\mathrm{O} 12$ atoms to build a inorganic Mo-chain (Fig. S3 $\dagger$ ). The $\mathrm{H}_{2}$ bdpm ligand exhibits a single coordination mode only, offering two apical $\mathrm{N}$ donors to link two $\mathrm{Cu}^{2+}$ ions to construct a $1 \mathrm{D}$ zigzag $\mathrm{Cu}-\mathrm{H}_{2}$ bdpm chain a
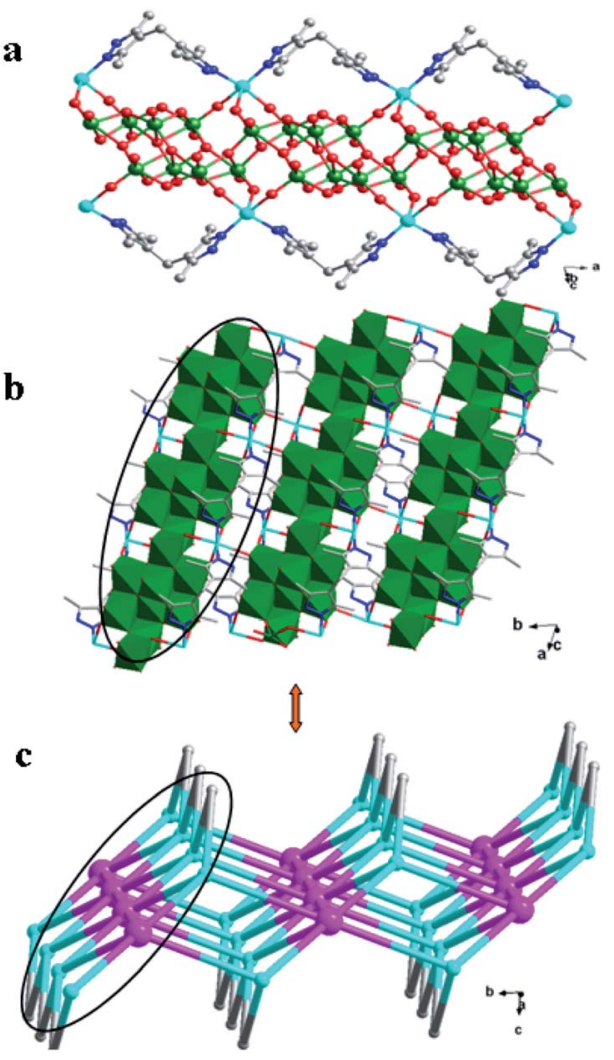

Fig. 9 (a) 1D "hamburger-like" chain of 4. (b) 2D layer of 4. (c) Schematic diagram of the $2 \mathrm{D}$ layer.

(Fig. S4 $\dagger$ ). The $\mathrm{H}_{2}$ bdpm with two symmetrical bis(pyrazole) groups induces the extensional metal-organic subunits. Two sets of $\mathrm{Cu}-\mathrm{H}_{2}$ bdpm chains cover the Mo-chain up and down, just like a "hamburger" chain, as shown in Fig. 9a. The adjacent hamburger chains are further linked by $\mathrm{Cu} 1-\mathrm{O} 9$ bonds to build a $2 \mathrm{D}$ layer, as shown in Fig. $5 \mathrm{~b}$ and $\mathrm{c}$.

Crystal structure of compound 5. Single-crystal X-ray structure analysis reveals that compound $\mathbf{5}$ consists of half a $\theta$-type $\mathrm{Mo}_{8}$ anion, one Hbhpe ligand and two $\mathrm{Ag}^{+}$atoms (Fig. 10). The $\theta-\mathrm{Mo}_{8}$ anion owns four $\left\{\mathrm{MoO}_{6}\right\}$ octahedra, two $\left\{\mathrm{MoO}_{5}\right\}$ and two $\left\{\mathrm{MoO}_{4}\right\}$ subunits. All Mo atoms are in the +VI oxidation state and all $\mathrm{Ag}$ atoms are in the $+\mathrm{I}$ oxidation state according to valence sum calculations. ${ }^{15}$

In compound $\mathbf{5}$, there are two crystallographically independent $\mathrm{Ag}$ ions (Ag1 and $\mathrm{Ag} 2)$ with two different coordination

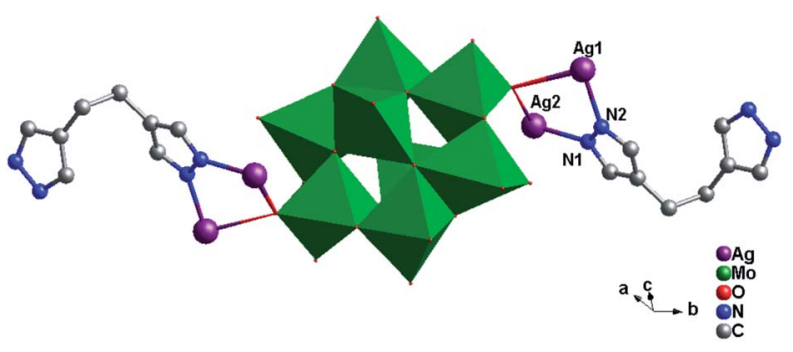

Fig. 10 Ball/stick view of the asymmetric unit of compound 5. The hydrogen atoms are omitted for clarity. 


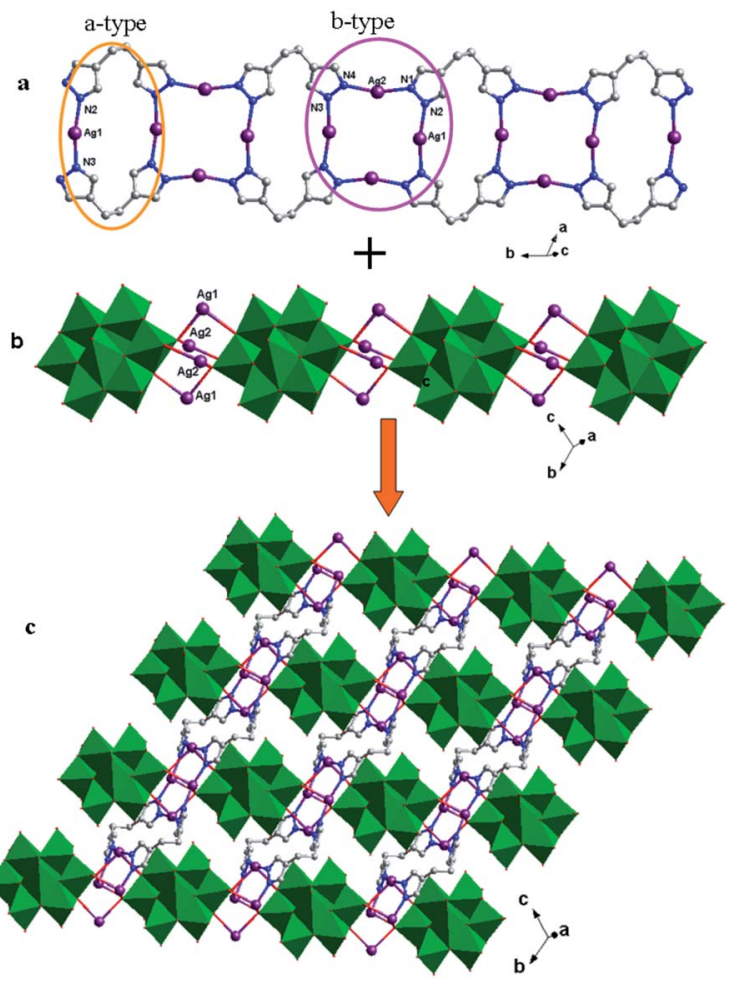

Fig. 11 (a) 1D metal-organic cycle-connecting-cycle chain of 5 with a-type (orange ellipse) and b-type cycles (purple ellipse) arranged alternately. (b) 1D inorganic chain of 5. (c) 2D layer with 1D metalorganic chains linking the inorganic chains vertically. geometries. Ag1 is six-coordinated with two $\mathrm{N}$ donors ( $\mathrm{N} 2$ and N3) from two Hbhpe ligands and four terminal O atoms (O5, O6, $\mathrm{O} 7$ and $\mathrm{O} 11)$ from three $\theta-\mathrm{Mo}_{8}$ anions, with $\mathrm{Ag}-\mathrm{N}$ bond distances of 2.208(5) and 2.212(5) $\AA$, Ag-O bond distances of 2.670(5)-2.819(5) $\AA$, and an N-Ag-N angle of 165.8(2) ${ }^{\circ}$ (Table $\mathrm{S} 1 \dagger)$. The Ag2 ion is four-coordinated with two $\mathrm{N}$ atoms (N1 and N4) from two Hbhpe ligands and two O atoms (O10 and O11) from two $\theta-\mathrm{Mo}_{8}$ anions. The bond distances and angles around $\mathrm{Ag} 2$ are 2.155(5) and 2.160(6) $\mathrm{A}$ for Ag-N, 2.511(5) and 2.617(5) for $\mathrm{Ag}-\mathrm{O}$ and $160.8(2)^{\circ}$ for $\mathrm{N}-\mathrm{Ag}-\mathrm{N}$.

In compound 5, the Hbhpe ligand provides four $\mathrm{N}$ atoms to link four $\mathrm{Ag}^{+}$ions, showing a "U" configuration. These two symmetrical pyrazole groups induce an extensional structure, a 1D cycle-connecting-cycle chain, as shown in Fig. 11a. In this chain, there are two types of cycle: a-type and b-type. The a-type cycle is a bi-nuclear one $\left[\mathrm{Ag}_{2}(\mathrm{Hbhpe})_{2}\right]^{2-}$ with two $\mathrm{Ag}^{+}$ions fused by two $\mathrm{H}_{2}$ bhpe ligands. The b-type cycle exhibits a tetranuclear cycle, in which four $\mathrm{Ag}^{+}$ions are aggregated by four ligands. The bi-nuclear $\left[\mathrm{Ag}_{2}(\mathrm{Hbhpe})_{2}\right]^{2-}$ cycle and tetra-nuclear $\left[\mathrm{Ag}_{4}(\mathrm{Hbhpe})_{4}\right]^{4-}$ cycle connect each other alternately through sharing the same $\mathrm{H}_{2}$ bhpe ligands and a cycle-connecting-cycle chain is formed. The $\theta-\mathrm{Mo}_{8}$ anions link the $\mathrm{Ag}^{+}$atoms in tetra-nuclear cycles to build a 1D inorganic chain (Fig. 11b). The metal-organic cycle-connecting-cycle chain links the inorganic chain vertically through sharing the tetra-nuclear cycles. Furthermore, a 2D layer of 5 is constructed (Fig. 11c).

The influence of pendant tea and symmetrical bis(pyrazol) ligands on dimensional extension of metal-organic subunits. In recent years, pendant ligands involving only one coordination group and flexible ligands with two symmetrical coordination

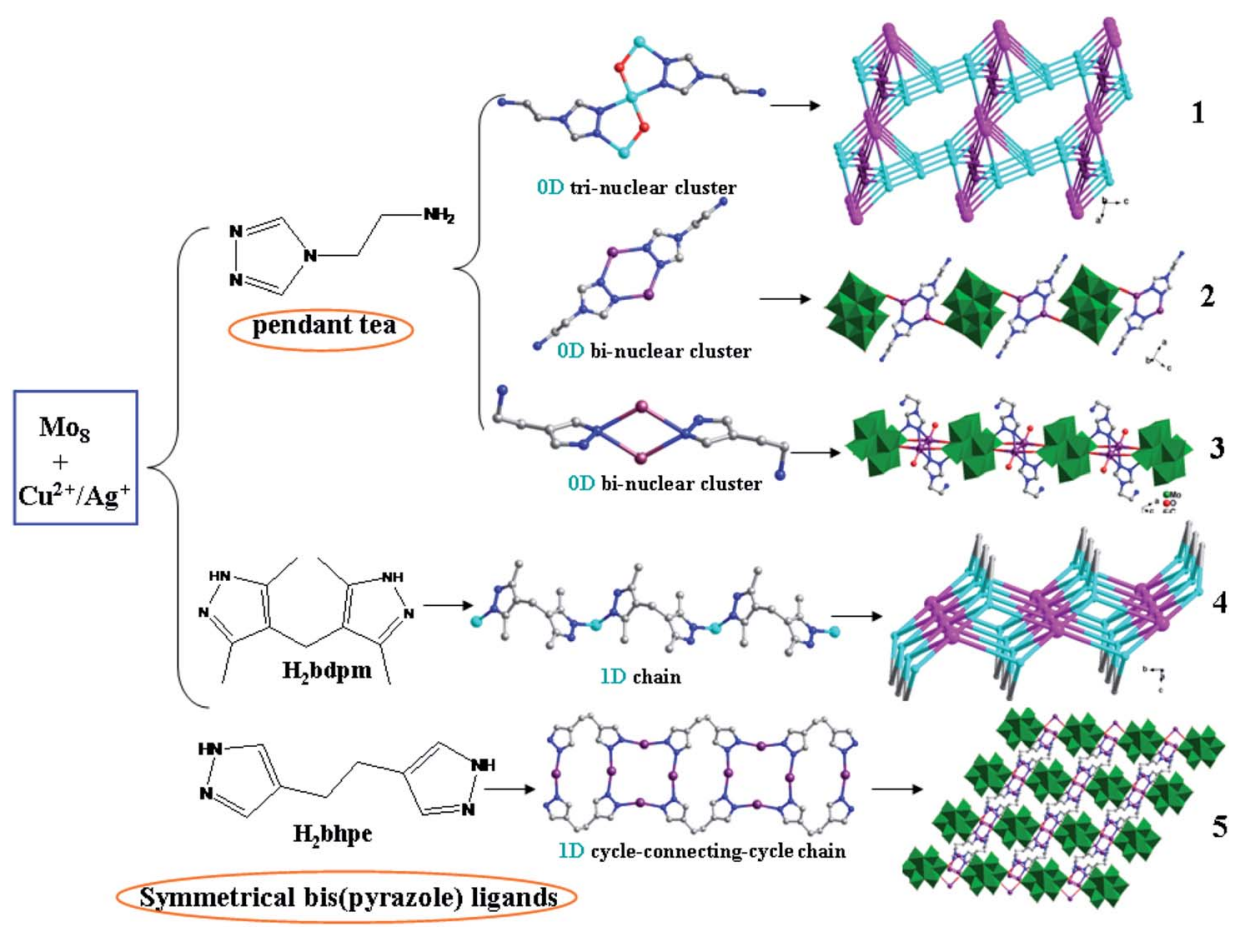

Scheme 1 Using pendant tea and symmetrical bis(pyrazole) ligands $\mathrm{H}_{2}$ bdpm and $\mathrm{H}_{2}$ bhpe to tune OD and 1D metal-organic subunits in compounds $1-5$. 
groups have attracted considerable attention for the construction of POM-TMCs. These two kinds of ligand show distinct coordination modes, which can induce different structures. In this work, we chose the pendant tea and symmetrical bis(pyrazole) ligands, $\mathrm{H}_{2}$ bdpm and $\mathrm{H}_{2}$ bhpe, to modify POM-Cu${ }^{2+} / \mathrm{Ag}^{+}$systems (Scheme 1). The tea owns one triazole group and one $-\mathrm{NH}_{2}$ group. However, the $-\mathrm{NH}_{2}$ unit is difficult to coordinate with metal ions, which prevent dimensional extension. Furthermore, the two $\mathrm{N}$ donors of tea are successive, forming low-dimensional multinuclear clusters. Compounds 1-3 have confirmed this point. In compound 1 , a linear tri-nuclear $\left[\mathrm{Cu}_{3}(\mathrm{tea})_{2}(\mathrm{OH})_{2}\right]^{4+}$ cluster has been built, showing a 0D metal-organic subunit. In compounds 2 and 3, bi-nuclear Ag clusters have been obtained, with no metalorganic extension. The $\mathrm{H}_{2}$ bdpm and $\mathrm{H}_{2}$ bhpe ligands have two symmetrical pyrazole groups, which can induce high-dimensional metal-organic structures, such as a 1D chain in $\mathbf{4}$ and a cycleconnecting-cycle chain in $\mathbf{5}$. Thus, using pendant and bis(pyrazole) ligands is a rational synthetic method to tune the dimensionality of metal-organic subunits in POM-based compounds.

\section{FT-IR spectra}

Fig. S5 $\uparrow$ shows the IR spectra of compounds 1-5. In the spectra, characteristic bands at 931, 879, 745, 627 and $1018 \mathrm{~cm}^{-1}$ for 1 , $968,879,754$ and $565 \mathrm{~cm}^{-1}$ for $2,938,825,673$ and $554 \mathrm{~cm}^{-1}$ for 3, 970, 880, 761 and $542 \mathrm{~cm}^{-1}$ for 4 and 964, 871, 766 and 534 $\mathrm{cm}^{-1}$ for 5 , are attributed to $\nu\left(\mathrm{Mo}-\mathrm{O}_{\mathrm{t}}\right), \nu\left(\mathrm{Mo}-\mathrm{O}_{\mathrm{b}}-\mathrm{Mo}\right), \nu\left(\mathrm{Mo}^{-} \mathrm{O}_{\mathrm{c}}{ }^{-}\right.$ $\mathrm{Mo}),{ }^{16}$ respectively. Bands in the regions of $1626-1116 \mathrm{~cm}^{-1}$ for $1,1637-1120 \mathrm{~cm}^{-1}$ for 2 and $1626-1112$ for $3,1634-1188 \mathrm{~cm}^{-1}$ for 4 and $1647-1186 \mathrm{~cm}^{-1}$ for 5 are attributed to the tea, Hbhpe and $\mathrm{H}_{2}$ bdpm ligands, respectively.

\section{Voltammetric behavior of 1-CPE in aqueous electrolyte and its electrocatalytic activity}

We studied the electrochemical properties of compounds 1-5. Owing to the similar electrochemical behaviors of compounds 1-5 modified carbon paste electrodes, 1-CPE has been used as a representative example to study the electrochemical properties. Cyclic voltammograms for 1-CPEs in $0.1 \mathrm{M} \mathrm{H}_{2} \mathrm{SO}_{4}+0.5 \mathrm{M}$

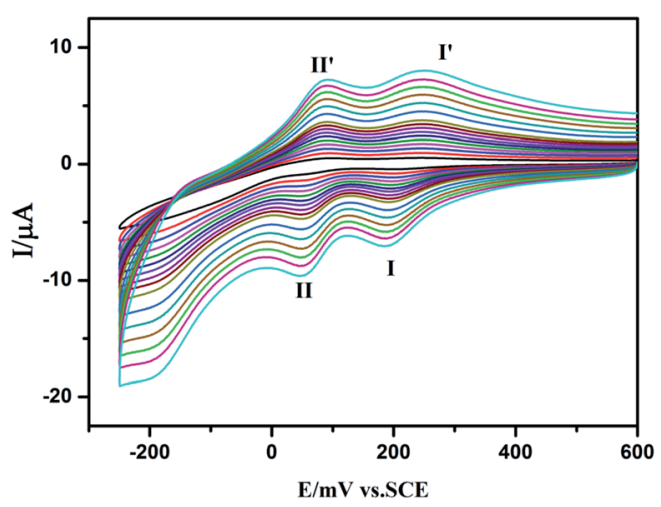

Fig. 12 Cyclic voltammograms of 1-CPE in $0.1 \mathrm{M} \mathrm{H}_{2} \mathrm{SO}_{4}+0.5 \mathrm{M}$ $\mathrm{Na}_{2} \mathrm{SO}_{4}$ aqueous solution at different scan rates (from inner to outer: $20,40,60,80,100,120,140,160,180,200,250,300,350,400,450$ and $500 \mathrm{mV} \mathrm{s}^{-1}$, respectively).
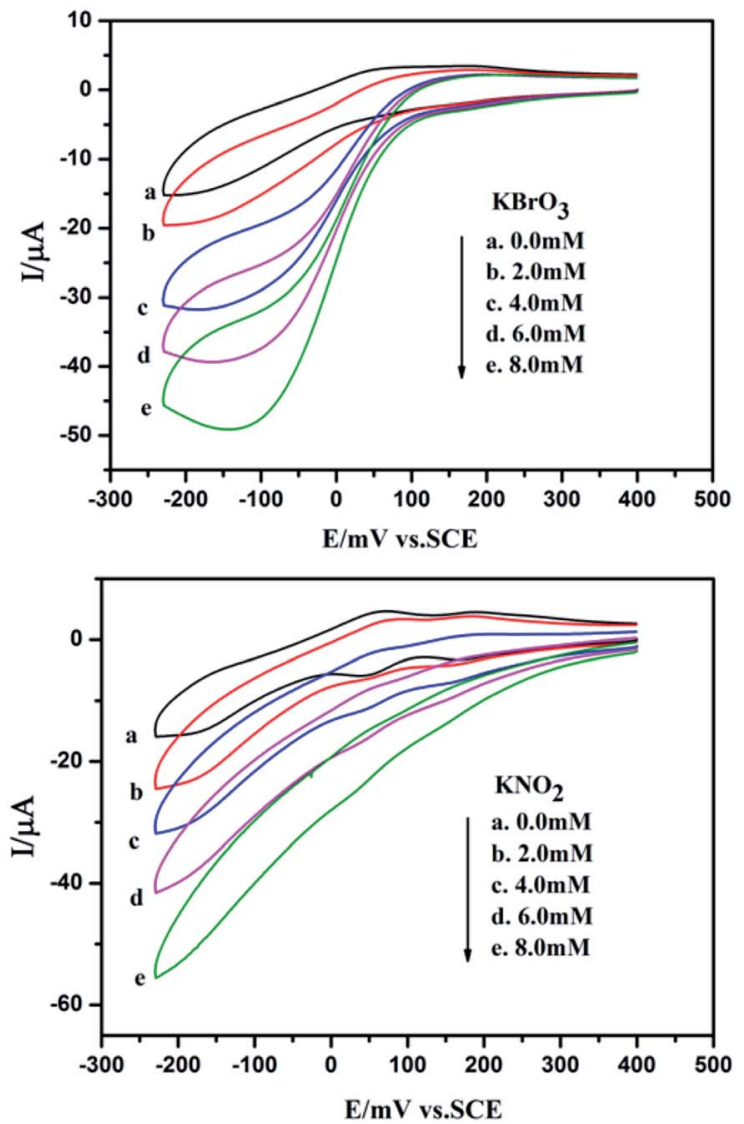

Fig. 13 Cyclic voltammograms of 1-CPE in $0.1 \mathrm{M} \mathrm{H}_{2} \mathrm{SO}_{4}+0.5 \mathrm{M}$ $\mathrm{Na}_{2} \mathrm{SO}_{4}$ containing 0 (a); 2.0 (b); 4.0 (c); 6.0 (d); 8.0 (e) mM nitrite/ bromate. Scan rate: $200 \mathrm{mV} \mathrm{s}^{-1}$.

$\mathrm{Na}_{2} \mathrm{SO}_{4}$ aqueous solution at different scan rates are presented in Fig. 12. In the potential range from +600 to $-250 \mathrm{mV}$, two

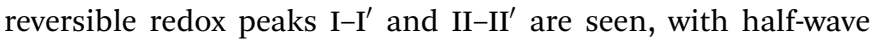
potentials $E_{1 / 2}=\left(E_{\mathrm{pa}}+E_{\mathrm{pc}}\right) / 2$ of $+228\left(\mathrm{I}-\mathrm{I}^{\prime}\right),+70\left(\mathrm{II}-\mathrm{II}^{\prime}\right) \mathrm{mV}$ (scan rate: $80 \mathrm{mV} \mathrm{s}^{-1}$ ). These two redox peaks should be ascribed to two consecutive two-electron process of $\mathrm{Mo}_{8} \cdot{ }^{17}$ From 20 to $500 \mathrm{mV} \mathrm{s}^{-1}$ of scan rates, the peak potentials change gradually: the cathodic peak potentials shift towards the negative direction, while the corresponding anodic peak potentials shift to the positive direction.

Fig. 13 shows cyclic voltammograms for the electrocatalytic reduction of nitrite and bromate at 1-CPE in $0.1 \mathrm{M} \mathrm{H}_{2} \mathrm{SO}_{4}+$ $0.5 \mathrm{M} \mathrm{Na}_{2} \mathrm{SO}_{4}$ aqueous solution. With the addition of bromate, the second reduction peak currents increase gradually, while the corresponding oxidation peak currents gradually decrease. However, the first redox peak remains almost unchanged. Furthermore, it can clearly be seen that with the addition of nitrite, both reduction peak currents gradually increased and the corresponding oxidation peak currents visibly decreased indicating that 1-CPE exhibits good electrocatalytic activity for the reduction of bromate and nitrite.

\section{Photocatalytic activity}

Under UV light irradiation, we selected two organic dyes, methylene blue (MB) and rhodamine B (RhB), as model 

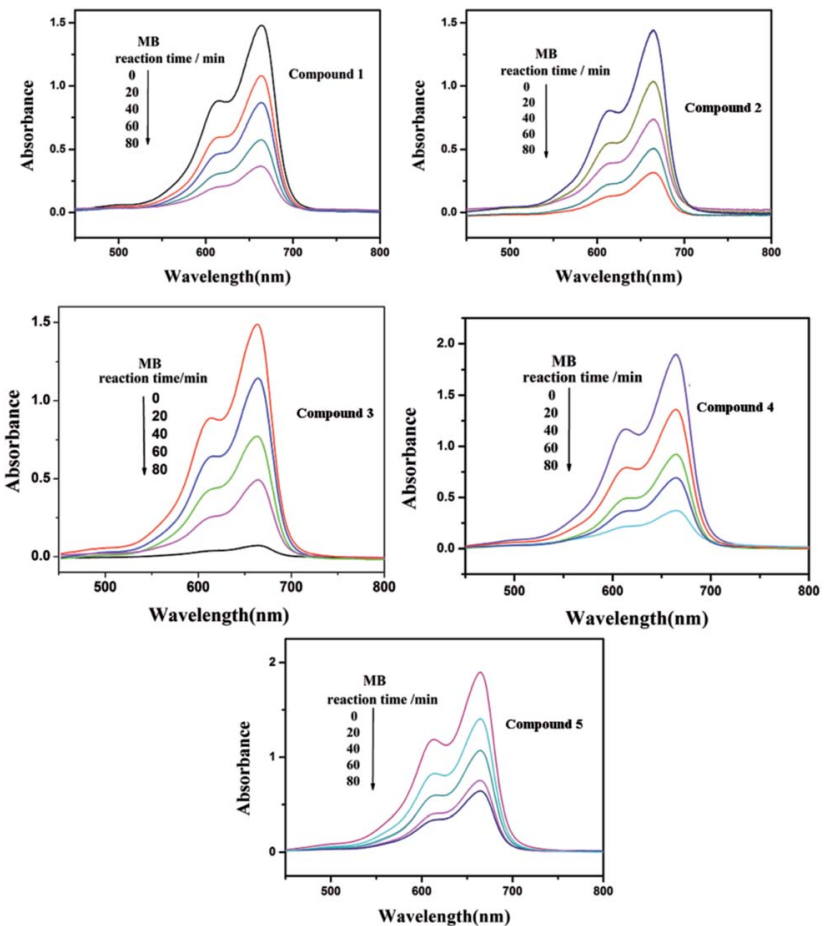

Fig. 14 Absorption spectra of the MB solution during the decomposition reaction under UV irradiation with the compounds $1-5$ as the catalyst.

pollutants in aqueous media to study the photocatalytic activities of compounds 1-5. In the process of photocatalysis, $150 \mathrm{mg}$ of compounds 1-5 were decentralized in $0.02 \mathrm{mmol} \mathrm{L}^{-1} \mathrm{MB}$ /
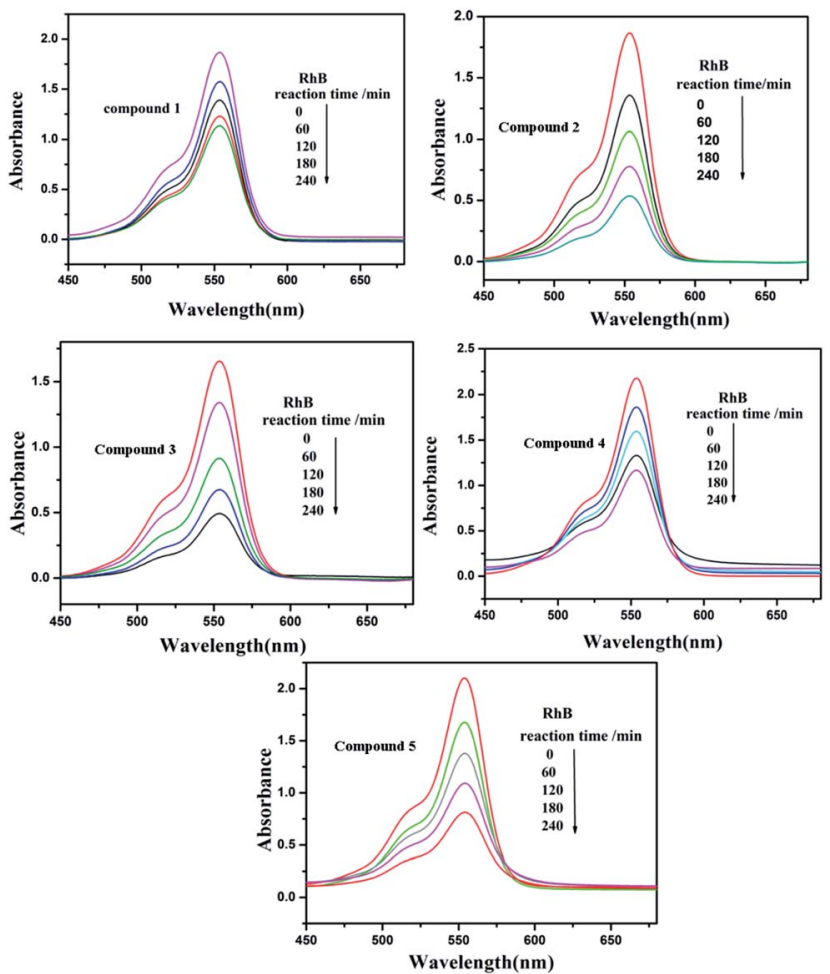

Fig. 15 Absorption spectra of the RhB solution during the decomposition reaction under UV irradiation with the compounds 1-5 as the catalyst.
RhB aqueous solution $(90 \mathrm{~mL})$ and magnetically stirred for about $10 \mathrm{~min}$ to ensure the equilibrium in the dark. Then the mixed solution was exposed to a UV $\mathrm{Hg}$ lamp with continuous stirring. At every interval (20 min for $\mathrm{MB}$ and $60 \mathrm{~min}$ for $\mathrm{RhB}$ ), $5.0 \mathrm{~mL}$ samples were removed for analysis by UV-Vis spectrophotometer. We can clearly see that the percentage of $\mathrm{MB}$ degradation photocatalyzed by 1-5 increased clearly with increasing reaction time (Fig. 14). The conversions of $\mathrm{MB}$ are $75 \%$ for $\mathbf{1}, 80.0 \%$ for $2,95.2 \%$ for $3,80.3 \%$ for 4 and $66.2 \%$ for 5 , after $80 \mathrm{~min}$ (Fig. S6a $\dagger$ ). Fig. 15 shows the photocatalytic degradation of RhB with the conversions of $39.5 \%$ for $1,71.1 \%$ for $2,70.3 \%$ for $3,46.3 \%$ for 4 and $61.4 \%$ for 5 , after $240 \mathrm{~min}$ (Fig. S6b $\dagger$ ). This result shows that compounds 1-5 have good photocatalytic activities for the degradation of $\mathrm{MB}$, while compounds 2, 3, 4 and 5 can act as good photocatalysts for the degradation of RhB.

\section{Conclusions}

In this paper, by using pendant tea and bis(pyrazole) ligands $\mathrm{H}_{2}$ bdpm and $\mathrm{H}_{2}$ bhpe, five new $\mathrm{Mo}_{8}$-based compounds have been synthesized under hydrothermal conditions. Single coordination group (tea) and two symmetrical bis(pyrazole) groups ( $\mathrm{H}_{2}$ bdpm and $\mathrm{H}_{2}$ bhpe) induce $\mathrm{OD}$ and $1 \mathrm{D}$ metal-organic subunits, respectively, in these five structures. The bis(pyrazole) ligands can induce extensional structures with ease. It is therefore rational to use pendant and bis(pyrazole) ligands to tune the metal-organic dimensionality of 1-5.

\section{Note added after first publication}

This article replaces the version published on 14th June 2017, which contained errors in the CCDC numbers.

\section{Acknowledgements}

Financial support of this research by the National Natural Science Foundation of China (No. 21571023, 21401010 and 21471021) and Talent-supporting Program Foundation of Education Office of Liaoning Province (LJQ2012097).

\section{Notes and references}

1 (a) R. Yu, X. F. Kuang, X. Y. Wu, C. Z. Lu and J. P. Donahue, Coord. Chem. Rev., 2009, 253, 2872; (b) J. W. Zhao, Y. Z. Li, L. J. Chen and G. Y. Yang, Chem. Commun., 2016, 52, 4418; (c) T. Ueda, M. Ohnishi, M. Shiro, J. I. Nambu, T. Yonemura, J. F. Boas and A. M. Bond, J. Am. Chem. Soc., 2014, 136, 10941; (d) A. Rubinstein, P. J. Lozanao, J. J. Carbó, J. M. Poblet and R. Neumann, J. Am. Chem. Soc., 2014, 136, 10941; (e) D. L. Long, E. Burkholder and L. Cronin, Chem. Soc. Rev., 2007, 36, 105.

2 (a) J. Q. Sha, J. W. Sun, M. T. Li, C. Wang, G. M. Li, P. F. Yan and L. J. Sun, Dalton Trans., 2013, 42, 1667; (b) P. Kar, R. Haldar, C. J. Gómez-García and A. Ghosh, Inorg. Chem., 2012, 51, 4265; (c) Z. J. Liu, X. L. Wang, C. Qin, Z. M. Zhang, Y. G. Li, W. L. Chen and E. B. Wang, Coord. 
Chem. Rev., 2016, 313, 94; (d) J. J. Walsh, A. M. Bond, R. J. Forster and T. E. Keyes, Coord. Chem. Rev., 2016, 306, 217.

3 (a) J. Zhou, X. Liu, R. Chen, H. P. Xiao, F. L. Hu, H. H. Zou, Y. Zhou, C. Liu and L. G. Zhu, CrystEngComm, 2013, 15, 5057; (b) J. Zhou, J. W. Zhao, Q. Wei, J. Zhang and G. Y. Yang, J. Am. Chem. Soc., 2014, 136, 5065.

4 (a) Z. G. Han, Y. Z. Gao and C. W. Hu, Cryst. Growth Des., 2008, 8, 1261; (b) S. L. Li, Y. Q. Lan, J. F. Ma, J. Yang, X. H. Wang and Z. M. Su, Inorg. Chem., 2007, 46, 8283.

5 Y. Q. Lan, S. L. Li, X. L. Wang, K. Z. Shao, D. Y. Du, H. Y. Zang and Z. M. Su, Inorg. Chem., 2008, 47, 8179.

6 Q. G. Zhai, X. Y. Wu, S. M. Chen, Z. G. Zhao and C. Z. Lu, Inorg. Chem., 2007, 46, 5046.

7 (a) P. J. Zapf, C. J. Warren, R. C. Haushalter and J. Zubieta, Chem. Commun., 1997, 1543; (b) P. J. Zapf, R. L. LaDuca, R. S. Rarig, K. M. Johnson and J. Zubieta, Inorg. Chem., 1998, 37, 3411; (c) J. R. D. DeBord, R. C. Haushalter, L. M. Meyer, D. J. Rose, P. J. Zapf and J. Zubieta, Inorg. Chim. Acta, 1997, 256, 165; (d) D. Hagrman, C. Zubieta, D. J. Rose, J. Zubieta and R. C. Haushalter, Angew. Chem., Int. Ed. Engl., 1997, 36, 873; (e) D. Hagrman, C. Sangregorio, C. J. O’Connor and J. Zubieta, J. Chem. Soc., Dalton Trans., 1998, 3707.

8 (a) J. Gu, X. E. Jiang, Z. H. Su, Z. F. Zhao and B. B Zhou, Inorg. Chim. Acta, 2013, 400, 210; (b) X. L. Wang, J. Li, A. X. Tian, G. C. Liu and H. Y. Lin, Sci. Sin.: Chim., 2011, 41, 806.

9 (a) B. X. Dong and Q. Xu, Inorg. Chem., 2009, 48, 5861; (b) X. L. Wang, X. J. Liu, A. X. Tian, J. Ying, H. Y. Lin, G. C. Liu and Q. Gao, Dalton Trans., 2012, 41, 9587.
10 (a) P. P. Zhang, J. Peng, A. X. Tian, H. J. Pang, Y. Chen, M. Zhu, D. D. Wang, M. G. Liu and Y. H. Wang, J. Mol. Struct., 2010, 984, 221; (b) B. X. Dong, J. Peng, C. J. GómezGarcía, S. Benmansour, H. Q. Jia and N. H. Hu, Inorg. Chem., 2007, 46, 5933.

11 (a) X. L. Wang, H. L. Hu, G. C. Liu, H. Y. Lin and A. X. Tian, Chem. Commun., 2010, 46, 6485; (b) X. L. Wang, H. L. Hu, A. X. Tian, H. Y. Lin and J. Li, Inorg. Chem., 2010, 49, 10299.

12 (a) A. X. Tian, J. Peng, J. Q. Sha, Z. G. Han, J. F. Ma, Z. M. Su, N. H. Hu and H. Q. Jia, Inorg. Chem., 2008, 47, 3274; (b) A. X. Tian, J. Ying, J. Peng, J. Q. Sha, Z. M. Su, H. J. Pang, P. P. Zhang, Y. Chen, M. Zhu and Y. Shen, Cryst. Growth Des., 2010, 10, 1104.

13 A. X. Tian, Y. L. Ning, J. Ying, X. Hou, Y. Tian, T. J. Li and X. L. Wang, Sci. Sin.: Chim., 2016, 46, 688.

14 G. M. Sheldrick, SHELXS-97, University of Göttingen, Germany, 1997.

15 I. D. Brown and D. Altermatt, Acta Crystallogr., Sect. B: Struct. Sci., 1985, 41, 244.

16 (a) W. G. Klemperer and W. Shum, J. Am. Chem. Soc., 1976, 98, 8291; (b) N. Xu, J. W. Zhang, X. L. Wang, G. C. Liu and T. J. Li, Dalton Trans., 2016, 45, 760; (c) C. RocchiccioliDeltcheff, M. Fournier and R. Franck, Inorg. Chem., 1983, 22, 207; (d) R. Thouvenot, M. Fournier, R. Franck and C. Rocchiccioli-Deltcheff, Inorg. Chem., 1984, 23, 598; (e) C. Rocchiccioli-Deltcheff, R. Thouvenot and R. Franck, Spectrochim. Acta, 1976, 32, 587.

17 (a) D. Hagrman, C. Sangregorio, C. J. O'Connor and J. Zubieta, Dalton Trans., 1998, 22, 3707; (b) F. Gruber and M. Jansen, Z. Anorg. Allg. Chem., 2010, 636, 2352. 